\title{
OBESIDADE INFANTIL E A FAMÍLIA: EDUCADORES EMOCIONAIS E NUTRICIONAIS DOS FILHOS
}

\author{
Infantile Obesity and the Family: Emotional and nutritionals \\ Educators of the Sons
}

Fernanda Ax Wilhelm ${ }^{l}$ Jenniffer Haranda Colombo Antunes de Lima² KeylaFranciani Schirmer ${ }^{3}$

\section{Resumo}

A ocorrência de obesidade infantil alcança índices preocupantes. A temática tem adquirido relevante importância, principalmente devido ao impacto que pode provocar na vida de crianças, trazendo conseqüências físicas, sociais, econômicas e psicológicas. O objetivo do estudo foi identificar os comportamentos e sentimentos presentes em crianças com obesidade indicados por suas mães e uma nutricionista que realiza acompanhamento nutricional com estas crianças em um serviço de saúde pública. Participaram do estudo uma nutricionista e quatro mães de crianças com idade entre 4 e 7 anos, que apresentam obesidade infantil. Na obtenção de dados sobre os comportamentos e sentimentos, foram utilizadas entrevistas semi-estruturadas com a nutricionista e com as mães. Os resultados obtidos indicam que a família possui papel fundamental no desenvolvimento físico, psíquico e moral das crianças, exercendo influência nos hábitos alimentares destas, sendo seus primeiros educadores emocionais e nutricionais. As crianças também acabam exercendo influência nos hábitos alimentares da família quando iniciam o acompanhamento nutricional, porque os pais necessitam mudar seus hábitos alimentares para auxiliar as crianças neste processo. Os principais sentimentos encontrados em crianças com obesidade foram os sentimentos de baixa auto-estima, ansiedade e culpa. O principal comportamento encontrado no contexto educacional foi o comportamento de bater nos coleguinhas durante o recreio escolar diante dos "deboches e comentários maldosos". No contexto familiar, referem-se ao comportamento da troca de favores com os pais e o comportamento de fazer chantagem com estes em relação a algum tipo de alimento.

Palavras-chave: Obesidade infantil; Alimentação e nutrição; Família.

\footnotetext{
Professora Universitária da Unidavi (Universidade para o Desenvolvimento do Alto Vale do Itajaí) e Orientadora da Pesquisa, Mestre em Psicologia pela UFSC. Santa Catarina, SC. e-mail: fernanda@unidavi.edu.br; fernandaax@gmail.com

Acadêmica de Psicologia da UNIDAVI. Santa Catarina, SC. e-mail: colombo.jenniffer@gmail.com

Acadêmica de Psicologia da UNIDAVI. Santa Catarina, SC. e-mail: psicoloira@ibest.com.br
} 


\section{Abstract}

The occurrence of infantile obesity reaches worrying registers. The subject has becoming important; mainly due to the shock it can cause in kids lives, bringing physic, social, economic and psychological consequences. The objective of this study was to identify the behaviour and the feelings in kids with obesity denoted by its mothers and by a nutritionist that develops a nutritional accompaniment with these kids in a health public job. There were a nutritionist and four mothers of kids between 4 and 7 years old that showed infantile obesity, involved in this research. To obtain the data related to the behaviour and feelings it was used semi-structuralized interviews with the nutritionist and with the mothers. The results indicate that the family has a basic role on physic, psychological and moral development of kids influencing in their feeding habits, the parents are the first emotional and nutritional educators. The kids also influence on the family's feeding habits when they start a nutritional accompaniment because their parents need to change their feeding habits to help them in this process. Low self-esteem, anxiety and fault were the mainly feelings found in these kids. The mainly behaviour found in the educational context was to beat on friends during the school break proceeded by "mockery and bad comments". In the familiar context they use to share favors with parents and to blackmail these ones related to any kind of food.

Keywords: Infantile obesity; Feeding and nourishment; Family.

\section{Introdução}

\section{Definindo e contextualizando a obesidade}

Estudos sobre a temática da obesidade infantil são relevantes e pertinentes por tratar-se de uma doença multifatorial. Suas causas podem ser genéticas, emocionais, socioeconômicas e culturais e devem ser consideradas singularmente (Barros, 1994). O fenômeno compreende variáveis biológicas, psicológicas, sociais e econômicas, sendo, portanto, considerada de etiologia multifatorial e que envolve aspectos ambientais e genéticos (Oliveira, Cerqueira \& Souza, 2003; Pinheiro, Freitas \& Corso, 2004). Acarreta repercussões orgânicas e psicossociais, cujo comportamento alimentar possui bases biológicas, sociais e aspectos psicológicos envolvidos em todas as idades (Bernardi, Cichelero, \& Vitolo, 2005).

Segundo dados fornecidos pelo Ministério da Saúde (1999), a obesidade, tanto em adultos quanto em crianças, está aumentando. Em relação à incidência, este fenômeno ocorre tanto nos países ricos como nos subdesenvolvidos, afetando inclusive países caracterizados por uma população magra, como é o caso do Japão. Tendo em vista a alta epidemiologia, a Organização Mundial da Saúde (OMS) passou a considerar a obesidade como um problema de saúde pública tão preocupante quanto a desnutrição (Organização Pan-Americana de Saúde-OPAS, 2003).
A obesidade infantil apresenta dimensões epidêmicas em alguns locais e ascendentes em outros. É um fenômeno universal, que no mundo acomete adultos e também crianças (17,6 milhões) com idades inferiores a cinco anos (Organização Pan-Americana de Saúde - OPAS, 2003).

$\mathrm{Na}$ literatura, são utilizados dois termos, sendo eles: obesidade (Ministério da Saúde) e excesso de peso (Organização Pan-Americana de Saúde Opas). Neste estudo, será utilizado o termo obesidade. Segundo Leão, Araújo, Moraes \& Assis (2003), a Organização Mundial da Saúde - OMS (1998) define a obesidade como o excesso de gordura corporal acumulado no corpo humano, ocasionando diferentes conseqüências à saúde. É definida ainda como excesso de gordura corporal relacionado à massa magra. Constitui uma doença crônica, caracterizada pelo excesso de gordura no corpo, que repercute em prejuízos à saúde global das pessoas (Ministério da Saúde, 1999).

É relevante conhecer o que as mães relatam sobre o fenômeno da obesidade infantil, visto que o ambiente familiar poderá propiciar condições que influenciam no desenvolvimento de distúrbios alimentares (Oliveira et al., 2003). A família deve ser orientada para o diagnóstico, causas e conseqüências desse fenômeno. É importante compreender as características dos aspectos psicológicos presentes e por meio do conhecimento científico colaborar para que tenham uma vida saudável e assim uma melhor qualidade de vida para todos os seus membros. 
O índice de massa corporal considerado normal para uma pessoa adulta é de 18,5 a 24,9. A prevalência do excesso de peso e a obesidade são avaliadas pelo Índice de Massa Corporal - IMC, definido como o peso em quilogramas dividido pelo quadrado da altura, em metros $\left(\mathrm{kg} / \mathrm{m}^{2}\right)$. Desse modo, IMCs superiores a $25 \mathrm{~kg} / \mathrm{m}^{2}$ caracterizam excesso de peso e IMCs superiores a $30 \mathrm{~kg} / \mathrm{m}^{2}$ são definidos como obesidade (OPAS, 2003).

Em relação aos adolescentes e crianças, é importante destacar que a avaliação da massa corporal nessa população é realizada por meio de tabelas que relacionam idade, peso e altura. Este sistema de avaliação é utilizado pelos profissionais da rede pública, cujo acompanhamento é feito nos postos de saúde, por meio da utilização do "Cartão da Criança”, com o objetivo de verificar a adequação da altura e do peso até a idade de cinco anos (Ministério da Saúde, 1999). A fórmula do IMC não é indicada para crianças e adolescentes porque estes estão em condição peculiar de desenvolvimento, acarretando em rápidas alterações corporais decorrentes do crescimento. Segundo Cataneo, Carvalho e Galindo (2005), a obesidade constitui, dentre as alterações corporais, o fenômeno mais complexo para definição e entendimento. É importante, portanto, analisá-la a partir do enfoque psicossocial (Bernardi et al., 2005; Oliveira et al., 2003; Pinheiro et al., 2004).

É possível verificar que no Brasil e demais países em desenvolvimento, cujo fenômeno da subnutrição é freqüente e preocupante, o aumento das taxas de obesidade está prevalecendo. As conseqüências para a saúde das pessoas são variadas, como, por exemplo, a ocorrência de doenças crônicas graves (hipertensão, doenças cardiovasculares, dentre outras) e em alguns casos o risco mais elevado de morte prematura. As inúmeras conseqüências reduzem de forma significativa a qualidade de vida das pessoas. Os fatores que acarretam a obesidade também são diversos, com influências sociais, genéticas e culturais.

Os processos de industrialização, urbanização, desenvolvimento econômico e globalização do mercado de alimentos são indicados como fatores relevantes, resultando em um consumo maior de alimentos de grande teor calórico e baixo teor nutritivo por pessoas que são menos ativas fisicamente (OPAS, 2003). Ainda conforme a referida organização, ao associar o surgimento de doenças crônico-degenerativas com a obesidade, estão sendo promovidas estratégias mundiais sobre hábitos de alimentação saudável e prática de atividades físicas. Sobre os hábitos de alimentação saudável, o Ministério da Saúde (1999) aponta que a reeducação alimentar é importante, porque visa a um novo estilo de vida a partir da ampliação de conceitos e mudanças de costumes e hábitos. A promoção de comportamentos saudáveis é fundamental para o incentivo à perda de peso em crianças e adultos para a garantia de uma melhor qualidade de vida, no presente e no futuro.

\section{Relação entre família e obesidade infantil}

O desenvolvimento constitui um importante processo para a formação da subjetividade do sujeito, ou seja, desde o nascimento, o ser humano se desenvolve em todos os aspectos (motor, físico, afetivo e cognitivo), influenciado pelos mais diversos contextos, sendo um destes a inserção em determinada família. Em relação às crianças obesas, a família é considerada importante agente para a prevenção ou manutenção da condição de obesidade e desempenha importante papel na educação alimentar no sentido de a família ter ou não hábitos saudáveis em seu cotidiano (Oliveira et al., 2003).

Cada família, por meio de sua forma particular de organização e dinâmica de vida, desempenha papel decisivo na educação formal e informal de seus filhos. Rego (1995), em seus estudos sobre a teoria vygotskyana, indica o interesse deste autor em compreender a relação entre os seres humanos e seu ambiente físico e social, atribuindo à cultura importante papel. Sobre a cultura, a autora indica que “[...] é parte constitutiva da natureza humana, já que sua característica psicológica se dá por meio da internalização dos modos historicamente determinados e culturalmente organizados de operar com informações" (Rego, 1995, p. 42). A família constitui a principal instituição mediadora nos primeiros anos de vida em que as crianças tornam-se participantes do mundo social em que estão inseridas. Conforme a teoria ecológica de Bronfenbrenner (2002, citado por Narvaz \& Koller, 2004, p. 52), “o desenvolvimento é caracterizado como um processo de interação recíproca, progressivamente mais complexa, entre a pessoa e seu contexto através da idéia de que o desenvolvimento ocorre ao longo do tempo". 
A teoria ecológica do desenvolvimento humano se refere ao estudo do ser humano em seus ambientes, sendo importante o exame do desenvolvimento e comportamentos "como um conjunto de funções das características da pessoa e do ambiente" (Copetti \& Krebs, 2004, p. 67). Conforme Bronfenbrenner (2002, p. 5), “o desenvolvimento é definido como uma mudança duradoura na maneira pela qual uma pessoa percebe e lida com o seu ambiente". Nesse sentido, "o desenvolvimento do sujeito humano se dá a partir das constantes interações com o meio social em que vive" (Vygotsky, 2003, citado por Rego, 1995, p. 60-61). O ser humano se desenvolve e aprende na interação com o outro, na troca, na relação. Sendo assim, é importante o estudo do fenômeno da obesidade, considerando o contexto em que as pessoas estão inseridas.

\section{Comportamentos e sentimentos presentes na obesidade infantil}

A obesidade pode repercutir diferentes processos psicológicos nas pessoas que a possuem. Conforme Bernardi et al. (2005), alguns aspectos psicológicos foram encontrados em pessoas obesas, tais como mudança de humor, distração, ansiedade e sentimento de culpa e perda de auto-estima.

Sobre a auto-estima, Bastos (2005) indica que a criança não nasce com este aspecto, sendo que surgirá e se desenvolverá durante sua vida e nas relações estabelecidas com os demais. É desenvolvida a partir de modos de olhar significativos que as crianças recebem desde os primeiros anos, em interação com o seu contex to social e o modo como a criança entende as coisas que estão no seu contexto, que lhe modelam a imagem e encerram importância fundamental para sua vida.

São vários os fatores que contribuem para o desenvolvimento da auto-estima na criança e o principal fator é o meio social onde esta criança está inserida. Segundo Bastos (2005, p. 90), "os primeiros meios sociais que a criança tem acesso são as instituições família e a escola e nestes contextos que começará a ter e trocar as suas primeiras experiências positivas ou negativas". De acordo com Assis e Avanci (2004, citado por Bastos, 2005, p. 81), estas instituições podem contribuir para a formação da auto-estima ou baixa auto-estima, considerando que nestes contextos as crianças se desenvolvem, tendo experiências positivas ou negativas. Segundo André e Lelord (2003, citado por Bastos, 2005, p. 94), a auto-estima é composta pelos sentimentos de "amor a si mesmo, a visão de si mesmo e a autoconfiança", que possibilitam desenvolver recursos que proporcionam condições para o seu êxito ou seu fracasso.

A obesidade pode acarretar no indivíduo possíveis questões relacionadas ao preconceito social e à discriminação. A falta de confiança, sensação de isolamento atribuída ao fracasso da família e das pessoas que convivem ao seu redor em entender fatores relacionados à obesidade, assim como a humilhação, decorrente do preconceito e discriminação que os indivíduos obesos estão sujeitos, podem remeter enorme carga psicológica ao obeso. De acordo com Cataneo et al. (2005), os aspectos psicológicos de pessoas obesas foram objetos de estudo, tendo-se como resultados obtidos que este fenômeno ocasiona uma carga psicológica em termos de sofrimento, que pode ser considerada como o maior efeito negativo da obesidade.

Rodrigues e Boog (2006) indicam que o estigma ${ }^{4}$, presente muitas vezes na obesidade em adolescentes, é carregado de intensa carga psicológica, procedendo do grupo social e da família. Segundo os autores, ser obeso pode ser, quase sempre, ser tratado de modo singular em relação à alimentação, ao vestuário, ser alvo de chacota e apelidos, ser sexualmente desinteressante na vida adulta, visto que o estigma e a discriminação podem demarcar obstáculos para efetivar mudanças no comportamento alimentar. Os sentimentos de frustração e medo, conseqüentes do estigma de "ser gordo (a)", podem impedir que os adolescentes problematizem as práticas cotidianas e acabem aumentando as dietas rígidas como estratégias imediatas, supostamente úteis para o tratamento da obesidade (Rodrigues \& Boog, 2006, p. 926).

No que diz respeito às crianças, os autores afirmam que estas apresentam dificuldades de lidar

\footnotetext{
O estigma refere-se às marcas - atributos sociais que um indivíduo, grupo ou povo carregam e cujo valor pode ser negativo ou pejorativo

[...] atributos facilmente reconhecíveis como carregados de um valor negativo para a maioria das pessoas (Bock, 1999, p. 209).
} 
com suas experiências de forma simbólica, de adiar satisfações e obter prazer nas relações sociais, além de baixa auto-estima e dependência materna. Cataneo et al. (2005) citam estudo realizado com 134 crianças cujos resultados obtidos indicaram que $76,8 \%$ das crianças apresentavam aspectos emocionais associados ao surgimento e à evolução da obesidade. Oliveira et al. (2003) apontam fatores potenciais para o desenvolvimento da obesidade, tais como mudança de escola e/ou cidade e também aqueles relacionados à dinâmica familiar, cujos aspectos podem produzir nos indivíduos sensações de angústia, ansiedade, depressão e desprazer. Spada (2005) ressalta que muitos aspectos podem estar ligados a esta situação, tais como: baixa auto-estima, pouco conhecimento de si mesmo, conturbada dinâmica familiar, baixa capacidade de vincular-se e estabelecer vínculos afetivos positivos e úteis ao crescimento pessoal, entre outros.

Desde a gestação e nos primeiros meses de vida, as emoções vão sendo introjetadas gradualmente e este fato depende de uma série de fatores, que, segundo Spada (2005, p.11), resultam de "fatores de aparato fisiológico, genético e ambientais, mas sobretudo o vínculo da mãe com seu filho, darão formas as experiências primitivas, que acompanharão o homem até o fim de sua vida". Sendo assim, é possível destacar o papel fundamental dos pais no desenvolvimento físico, psíquico e moral de seus filhos. Os pais são considerados os primeiros educadores emocionais e nutricionais das crianças (Spada, 2005).

Rodrigues e Boog (2006) afirmam em estudo realizado com adolescentes que os problemas psicológicos, sociais e comportamentais podem ocorrer em indivíduos obesos, prejudicando seu funcionamento físico e psíquico, tendo um impacto negativo em sua qualidade de vida por aspectos referentes à imagem corporal indesejada e problemas psicossociais. Nesse contexto, aparece o estigma na vida cotidiana dos jovens obesos.

Alguns transtornos psicológicos, tais como depressão, ansiedade e dificuldade de ajustamento social, podem ser observados em indivíduos com obesidade, seja endógena ou exógena. Segundo Spada (2005), o meio ambiente, aspectos emocionais, culturais, econômicos, sociais, ingestão de alimentos de alto valor calórico, diminuição da atividade física e estrutura familiar são importantes conjuntos de fatores que podem acarretar a obesidade.
A obesidade está relacionada a fatores psicológicos, como o controle, a percepção de si, a ansiedade e o desenvolvimento emocional de crianças e adolescentes. Em relação à percepção de si, o que a pessoa pensa sobre si mesma é importante no que diz respeito à satisfação que extrai de sua vida e das atividades que realiza, sendo um fator de risco ou de suporte para sua saúde mental. Em relação à ansiedade, é considerada como um estado emocional transitório ou condição do organismo humano que é caracterizada por sentimentos desagradáveis de tensão e apreensão, conscientemente percebidos e por aumento na atividade do sistema nervoso autônomo (Cataneo et al., 2005).

Considerando que diferentes aspectos emocionais podem estar associados à obesidade, favorecendo muitas vezes o desenvolvimento de problemas psicológicos e dificuldades comportamentais, é fundamental, então, compreender o fenômeno da obesidade infantil, principalmente relacionados aos aspectos psicológicos presentes, tendo em vista as conseqüências que podem produzir nos sujeitos na infância e ao longo de suas vidas (Luiz, Gorayeb, Liberatore Júnior \& Domingos, 2005).

\section{Método}

Foram sujeitos mães de quatro crianças na faixa etária entre 04 a 07 anos que possuem obesidade e que realizam acompanhamento nutricional com uma nutricionista em um serviço de saúde pública. Foi também sujeito da pesquisa a nutricionista que realiza acompanhamento nutricional com estas crianças.

A nutricionista possui dois cursos de especialização na área de obesidade, está formada há 3 anos e 5 meses e trabalha 3 anos na saúde pública. As mães possuem idades diferenciadas entre 25 a 45 anos de idade. A indicação de nomes das mães foi disponibilizada pela nutricionista que atende a estas crianças.

$\mathrm{Na}$ obtenção de dados, foram utilizados Roteiro de entrevista semi-estruturada com a nutricionista e Roteiro de entrevista semiestruturada com as mães. Todos os sujeitos (as mães) e a nutricionista assinaram o Termo de Consentimento Livre e Esclarecido (TCLE). As entrevistas foram gravadas e posteriormente transcritas e analisadas. 


\section{Resultados}

Cada participante da pesquisa recebeu uma nomenclatura diferenciada para preservar o seu anonimato: Nutricionista (N); Mães e Crianças (Mãe 1; Criança 4 anos); (Mãe 2; Criança 7 anos); (Mãe 3; Criança 7 anos); (Mãe 4; Criança 7 anos).

\section{Comportamentos apresentados pelas mães}

Foram identificados os tipos de comportamentos apresentados pelas mães em situações de almoços dominicais e nas festas de aniversário, sendo: Brigar com a criança, Consolar a criança ou Conversar com a criança. O comportamento de Conversar com a criança obteve maior ocorrência, onde três mães responderam que apresentam este comportamento nestas situações, conforme dados contidos no Gráfico 1:

\section{Gráfico 1 - Tipos de comportamentos apresentados pelas mães nas situações de almoços dominicais e festas de aniversário}

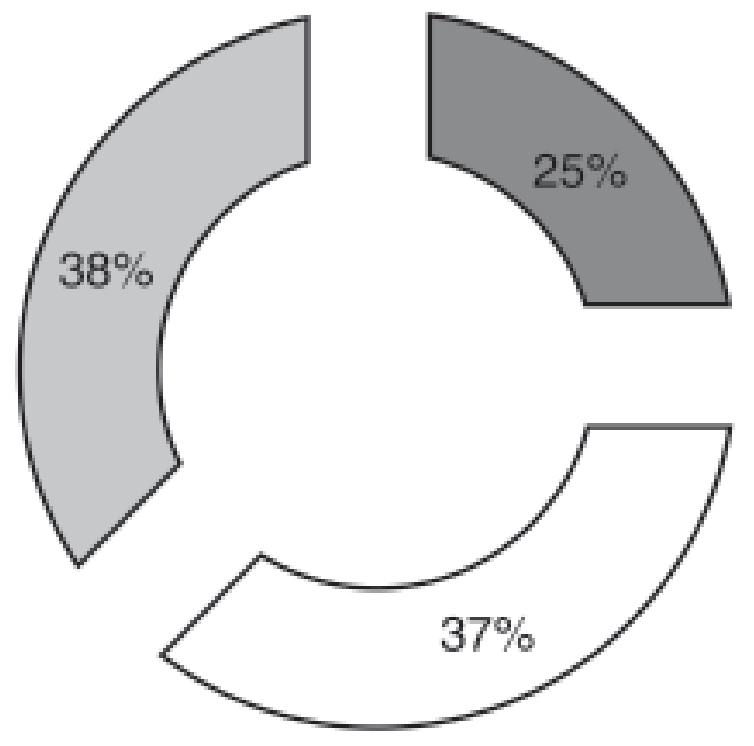

\section{Brigar com a criança}

A obesidade está relacionada a vários fatores, dentre eles, os fatores familiares a partir, por exemplo, das relações mantedoras de dependência e baseadas em cuidados básicos que impedem a individualização de seus membros, conflitos encobertos e regras muito fixas no interior da família (Spada, 2005).

Os pais podem apresentar o comportamento de troca de favores, de recompensa com a criança e com isso acabam ensinando esta a fazer chantagem. As crianças aprendem a "chantagear" psicologicamente os pais e vice-versa, prejudicando o seu processo de acompanhamento com a nutricionista. A fala abaixo comprova este fato:

Freqüentemente as crianças apresentam os comportamentos de chantagem com a família, porque os pais propõem a troca de favores, a recompensa, os pais recompensam a criança com alguma coisa, exemplo se você fizer o acompanhamento eu te dou um pirulito, um presente, etc.; $\mathrm{E}$ a criança faz chantagem com os pais, exemplo eu até faço o acompanhamento, mais se você me der um presente. $(\mathrm{N})$ 
Conforme Bronfenbrenner (2002, p. 5), “o desenvolvimento é definido como uma mudança duradoura na maneira pela qual uma pessoa percebe e lida com o seu ambiente". Nesse sentido, "o desenvolvimento do sujeito humano se dá a partir das constantes interações com o meio social em que vive" (Vygotsky, 2003, citado por Rego, 1995, p. 6061). Sendo assim, é possível afirmar que o ser humano se desenvolve e aprende na interação com o outro, na troca, ou seja, na relação. Neste estudo, é possível que as crianças aprendam o comportamento de fazer chantagem na relação com seus pais, na troca de comportamentos com o outro, na maneira pela qual percebem o ambiente onde estão inseridas.

\section{Comportamentos apresentados pelas crianças}

As crianças apresentam diferentes comportamentos e sentimentos frente a diferentes situações e concomitantemente suas mães também

\section{Tabela 1 - Comportamentos e sentimentos observados nos almoços dominicais pelas mães de crianças com obesidade}

\begin{tabular}{ccc}
\hline MĀES & $\begin{array}{c}\text { Tipos de comportamentos apresentados } \\
\text { pelas crianças diante da quantidade de } \\
\text { alimentos consumidos }\end{array}$ & $\begin{array}{c}\text { Tipos de comportamentos } \\
\text { apresentados pelas crianças } \\
\text { diante da quantidade de } \\
\text { sobremesa consumida }\end{array}$ \\
\hline 1 & Culpar a măe & Culpar a mãe \\
2 & Ansiedade & Ansiedade \\
3 & Ansiedade & Ansiedade \\
4 & Culpar-se & Culpar-se \\
\hline
\end{tabular}

indicam seus sentimentos e comportamentos. Esses aspectos podem ser visualizados nas Tabelas de 1 a 5 .

$\mathrm{Na}$ Tabela 1, os dados possibilitam constatar a ocorrência predominante para os sentimentos de culpa e ansiedade como tipos de comportamentos apresentados pelas crianças.
É possível verificar, conforme dados contidos na Tabela 2, que em relação à quantidade de alimentos consumidos durante os almoços dominicais, as crianças apresentam sentimentos de baixa auto-estima, raiva e tristeza. Já suas mães demonstram os sentimentos de raiva, tristeza e baixa auto-estima.

\section{Tabela 2 - Comportamentos e sentimentos observados nos almoços dominicais pelas mães de crianças com obesidade}

\begin{tabular}{|c|c|c|}
\hline MĀES & $\begin{array}{l}\text { Tipos de sentimentos apresentados } \\
\text { pelas crianças diante da quantidade de } \\
\text { alimentos consumidos }\end{array}$ & $\begin{array}{l}\text { Tipos de sentimentos } \\
\text { apresentados pelas crianças } \\
\text { diante da quantidade de } \\
\text { sobremesa consumida }\end{array}$ \\
\hline \multirow{2}{*}{1} & \multirow{2}{*}{ Baixa auto-estima } & Raiva \\
\hline & & Brigar com a criança \\
\hline \multirow{2}{*}{2} & \multirow{2}{*}{ Raiva } & Baixa aulo-estima \\
\hline & & Consolar a criança \\
\hline \multirow{2}{*}{3} & \multirow{2}{*}{ Tristeza } & Baixa auto-estima \\
\hline & & Conwersar com a criança \\
\hline \multirow{2}{*}{4} & \multirow{2}{*}{ Tristeza } & Tristeza \\
\hline & & Consolar a criança \\
\hline
\end{tabular}




\section{Tabela 3 - Comportamentos e sentimentos observados nas festas de aniversário pelas mães de crianças com obesidade}

\begin{tabular}{ccc}
\hline MĀES & $\begin{array}{c}\text { Tipos de comportamentos apresentados } \\
\text { pelas crianças diante da quantidade de } \\
\text { alimentos consumidos }\end{array}$ & $\begin{array}{c}\text { Tipos de comportamentos } \\
\text { apresentados pelas crianças } \\
\text { diante de possiveis } \\
\text { "deboches" dos coleguinhas }\end{array}$ \\
\hline 1 & Culpar a măe & Revolta \\
2 & Ansiedade & Bater \\
3 & Ansiedade & Bater \\
\hline & Culpar-se & Chorar \\
\hline
\end{tabular}

Seus comportamentos se referem a brigar, conversar e consolar a criança.

Conforme dados contidos na Tabela 3, em relação às festas de aniversário, os comportamentos apresentados pelas crianças são de culpa e ansiedade. Diante de "deboches" por parte de seus "coleguinhas",

\section{Tabela 4 - Comportamentos e sentimentos observados nas crianças diante da situação de não receber convites para festas de aniversário}

\begin{tabular}{cccc}
\hline MĀES & $\begin{array}{c}\text { Tipos de comportamentos } \\
\text { apresentados pelas crianças } \\
\text { diante do fato de năo receber } \\
\text { convites para algum } \\
\text { aniversário }\end{array}$ & $\begin{array}{c}\text { Tipos de } \\
\text { sentimentos } \\
\text { apresentadios } \\
\text { pelas crianças }\end{array}$ & $\begin{array}{c}\text { Tipos de sentimentos e } \\
\text { comportamentos apresentados } \\
\text { pelas măes }\end{array}$ \\
\hline 1 & Chorar & Baixa auto-estima & $\begin{array}{c}\text { Tristeza } \\
\text { Brigar com a criança } \\
\text { Raiva }\end{array}$ \\
3 & Chorar & Tristeza & $\begin{array}{c}\text { Conversar com a criança } \\
\text { Tristeza }\end{array}$ \\
4 & $\begin{array}{c}\text { Sempre é convidado para ir as } \\
\text { festas de aniversário } \\
\text { Chorar }\end{array}$ & Tristeza & $\begin{array}{c}\text { Conversar com a criança } \\
\text { Baba auto-estima } \\
\text { Consolar a criança }\end{array}$ \\
\hline
\end{tabular}

estas crianças apresentam os comportamentos de revolta, bater e chorar.

$\mathrm{Na}$ Tabela 4, os dados possibilitam constatar a ocorrência predominante para o comportamento de chorar da criança diante do fato de não ser convidada para festas de aniversários. Seus sentimentos são de baixa auto-estima e tristeza. Suas mães apresentam como sentimentos tristeza, raiva e 


\section{Tabela 5 - Comportamentos e sentimentos observados na escola pelas mães de crianças com obesidade}

\begin{tabular}{cccc}
\hline MÃES & $\begin{array}{c}\text { Tipos de } \\
\text { comportamentos } \\
\text { apresentados pelas } \\
\text { crianças diante de } \\
\text { possiveis comentários }\end{array}$ & $\begin{array}{c}\text { Tipos de comportamentos } \\
\text { apresentados pelas crianças } \\
\text { diante de comportamentos } \\
\text { na sala de aula antes } \\
\text { do recreio }\end{array}$ & $\begin{array}{c}\text { Tipos de sentimentos } \\
\text { apresentados pelas } \\
\text { crianças diante de } \\
\text { possiveis comentários } \\
\text { "maldosos" dos } \\
\text { amiguinhos }\end{array}$ \\
\hline 1 & Revolta & Comer na sala de aula & Baica auto-estima \\
3 & Bater & $\begin{array}{c}\text { Ficar pensando na hora do } \\
\text { lanche durante a aula } \\
\text { Comer na sala de aula }\end{array}$ & Raiva \\
4 & Bater & Raiva & Baba auto-estima \\
\hline
\end{tabular}

baixa auto-estima e como comportamentos brigar, conversar e consolar a criança.

Segundo dados contidos na Tabela 5, durante o recreio escolar, os tipos de comportamentos apresentados pelas crianças são de revolta, bater e chorar. Anteriormente ao recreio, o comportamento de falta de atenção apresentado pelas crianças pode estar relacionado ao fato de comer em sala de aula, ficar pensando na hora do lanche e sair da sala de aula para comer.

Os tipos de sentimentos apresentados pelas crianças diante de possíveis comentários são de raiva e baixa auto-estima.

\section{Discussão}

São muitas as bases que contribuem para o comportamento alimentar de uma criança. $\mathrm{O}$ comportamento alimentar não somente de crianças, mas de qualquer indivíduo, possui bases biológicas (organismo da pessoa), bases sociais (meio social a que a pessoa está inserida) e bases psicológicas (aspectos psicológicos da pessoa) que são os comportamentos e sentimentos que pode apresentar diante de diferentes situações.

De acordo com Cataneo et al. (2005, p. 524), "a obesidade cria uma enorme carga psicológica em termos de sofrimento, esta carga pode ser o maior efeito adverso da obesidade". Rodrigues e Boog (2006) contribuem com esta afirmação indicando que o estigma da obesidade é carregado de intensa carga psicológica relacionada à alimentação e ao vestuário. A criança que é obesa possui mais motivos para ser alvo de comentários "maldosos" e de possíveis "deboches" dos amiguinhos, o que pode gerar sofrimento psíquico para esta, ocasionando intensa carga psicológica. Sobre a ansiedade e o sentimento de culpa indicados na Tabela 1, autores como Bernardi et al. (2005) ressaltam que estes tipos de sentimentos são alguns dos aspectos psicológicos que foram encontrados em pessoas com obesidade.

A Tabela 2 e a Tabela 4 indicam sentimentos relacionados à auto-estima. A autoestima não é resultado de uma aprendizagem, surge nas interações com as outras pessoas provenientes dos meios sociais onde a pessoa está inserida. E, neste caso, o sentimento de baixa auto-estima apresentado pelas mães nestas situações surge das experiências, das interações destas com seus filhos. As mães vivenciam com as crianças possíveis experiências negativas que ocorrem no cotidiano de um indivíduo que possui obesidade. [...] A auto-estima é uma combinação de inúmeras experiências, interações e informações provenientes do meio, e não o resultado de um êxito, um comentário e uma aprendizagem (Feldman, 2002, citado por Bastos, 2005, p. 88).

São vários os fatores que contribuem para o desenvolvimento da auto-estima na criança, sendo o principal fator o meio social onde está inserida. Segundo Bastos (2005, p. 90), "os primeiros meios sociais que a criança tem acesso são as instituições família e a escola e nestes contextos começará a ter e trocar as suas primeiras experiências positivas ou 
negativas". Portanto, é possível afirmar que as crianças que possuem obesidade podem apresentar sentimentos de baixa auto-estima quando vivenciarem em algumas dessas instituições experiências onde existam fracassos e reações negativas, como experiências de discriminações sociais, preconceitos dos colegas, comentários maldosos e "deboches". Essas experiências negativas nas crianças podem gerar um sofrimento psicológico muito intenso.

A partir dos dados contidos na Tabela 5, é importante ressaltar que o comportamento de falta de atenção na criança pode ser causado pelo fator individual psíquico. Este fator funciona em torno do excesso de alimentação que a pessoa consome, onde a pessoa é tomada por um desconforto emocional, por uma tensão que não consegue controlar e sente que tem que ingerir algum alimento para aliviar isso. É necessário investigar os motivos que levam as crianças a antecipar o lanche na sala de aula uma vez que podem interferir diretamente em seu desempenho escolar. Estas podem estar sofrendo de um tipo de desconforto emocional, causado pelo fator individual psíquico, e quando as crianças comem o lanche, não comem porque necessariamente sentem fome, no entanto, comem para aliviar a tensão causada por este desconforto emocional (Spada, 2005).

Um fator que pode contribuir para a superação dessas experiências é o apoio emocional que a família oferece à criança. A família exerce fundamental importância no desenvolvimento da auto-estima nessas crianças. É importante que os pais saibam como lidar com essas experiências negativas que as crianças têm por conseqüência de ser um indivíduo que possui obesidade e que os pais tenham conhecimento científico sobre o fenômeno da obesidade.

\section{Considerações finais}

A obesidade infantil constitui uma temática complexa, que necessita ser analisada tendo em vista diversos fatores (familiares, econômicos, culturais, dentre outros). Neste estudo, foram constatados diferentes comportamentos e sentimentos presentes em crianças com obesidade, tais como baixa auto-estima, ansiedade e culpa. Os principais comportamentos encontrados no contexto educacional foram o comportamento de bater nos colegas durante o recreio escolar diante dos possíveis "deboches e comentários maldosos". Os principais comportamentos encontrados no contexto familiar referem-se ao comportamento da troca de favores com os pais e o comportamento de fazer chantagem com esses pais em relação a algum tipo de alimento.

Os resultados indicam que a família possui papel fundamental no desenvolvimento global de seus membros, ou seja, desenvolvimento físico, motor, psíquico e moral. Em relação aos hábitos alimentares, os pais exercem influência fundamental, sendo "os primeiros educadores emocionais e nutricionais dos filhos" (Spada, 2005). E concomitantemente, as crianças também exercem influência nos hábitos alimentares dos pais quando iniciam o acompanhamento nutricional, porque estes necessitam mudar seus hábitos alimentares para auxiliar os filhos neste processo, sendo que na maioria das vezes isso não acontece e os pais não continuam o acompanhamento.

Este estudo aponta para a importância de se realizar social e cientificamente estudos voltados aos comportamentos e sentimentos de pessoas com obesidade, principalmente em crianças. Estudos que envolvessem uma população maior, onde as entrevistas fossem dirigidas não somente para a profissional nutricionista e para as mães, mas para as próprias crianças e ainda para demais profissionais que atuam com crianças nos mais diversos contextos.

É importante realizar acompanhamentos sistemáticos com as famílias das crianças com obesidade, como, por exemplo, propostas de criação de grupos de apoio, equipe multidisciplinar para trabalhar em conjunto com estas famílias, criação de grupos de reflexão na escola para orientar os educadores sobre a temática, possíveis dúvidas e também para saber como lidar em determinadas situações, como, por exemplo, as questões de preconceito que surgem no contexto escolar.

Portanto, é necessário, diante deste fenômeno que cresce diariamente, relevante e pertinente, que sejam desenvolvidas políticas públicas voltadas para a prevenção e acompanhamento das pessoas que possuem obesidade e seus familiares, que constituem importante fonte de apoio. Também é importante, a partir do conhecimento de que o Brasil possui elevados índices de desnutrição e obesidade, a 
promoção contínua de ações de prevenção e principalmente conscientização sobre a importância de mudar hábitos de vida relacionados ao sedentarismo e à má alimentação para o entendimento sobre a importância de hábitos saudáveis no cotidiano. Pensar ações que envolvam a sociedade de maneira geral em todos os contextos, seja a família, a escola, os serviços de saúde, os profissionais de saúde e educação, enfim, que todos os cidadãos possam intervir e viver uma vida mais satisfatória.

É esperado que esta pesquisa possa ser o ponto de partida para futuras pesquisas, auxiliando de forma adequada a intervenção dos diversos profissionais, os obesos, suas famílias bem como a sociedade de forma geral, na perspectiva de uma melhor qualidade de vida a todos.

\section{Referências}

Barros, C. A. S. M. (1994). Alcoolismo, obesidade, consultoria psiquiátrica. Porto Alegre: Coleção Ensaios.

Bastos B. S. M. P. (2005). A auto-estima da criança que sofre violência física pela família. Dissertação de Mestrado, Programa de Pós Graduação em Psicologia, Centro de Ciências Humanas, Letras e Artes, Universidade Federal do Rio Grande do Norte, Natal.

Bernardi, F., Cichelero, C, \& Vitolo, M. R. (2005). Comportamento de restrição alimentar e obesidade. Revista de Nutrição, 18(1). Recuperado em 30 de mar 2005, SciELO (Sientific Eletronic Library On Line): www.scielo.br

Bock, A. A. M., Furtado, O., \& Teixeira, M. L. T. (1999). Psicologias: Uma introdução ao estudo de psicologia. São Paulo: Saraiva.

Bronfenbrenner, U., \& Veronese, M. A. A. V. (Trad.). (2002). A ecologia do desenvolvimento humano: Experimentos naturais e planejados. Porto Alegre: Artes Médicas.

Cataneo, C., Carvalho, A M. P., \& Galindo, E. M. C. (2005). Obesidade e aspectos psicológicos: maturidade emocional, autoconceito, lócus de controle e ansiedade. Psicologia: Reflexão e Crítica, 18(1). Recuperado em 15 mar. 2005, as SciELO (Sientific Eletronic Library On Line): www.scielo.br
Copetti, F., \& Krebs, R. J. (2004). As propriedades da pessoa na perspectiva do paradigma ecológico. In S. Koller (Org.), Ecologia do desenvolvimento humano (pp.67-89). São Paulo: Casa do Psicólogo.

Leão, L. de Souza; Araújo, L. M. B., Moraes, L. T. L. Pimenta de, \& Assis, A. M. (2003). Prevalência de obesidade em escolares de Salvador, Bahia. Arquivos Brasileiros de Endocrinologia \& Metabologia, 47(2). Recuperado em 15 de mar 2005, as SciELO (Sientific Eletronic Library On Line): www.scielo.br

Luiz, A. M. Â. G, Gorayeb, R., Liberatore Júnior, R. D. R., \& Domingos, N. A. M. (2005). Depressão, ansiedade e competência social em crianças obesas. Estudos de Psicologia. 10(1). Recuperado em 15 de mar 2005, as SciELO (Sientific Eletronic Library On Line): www.scielo.br

Ministério da Saúde. (1999). Obesidade e desnutrição. Brasília: Secretaria de Políticas de Saúde.

Narvaz, M. G., \& Koller, S. H. (2004). O Modelo bioecológico do desenvolvimento humano. In S. Koller (Org.), Ecologia do desenvolvimento humano (pp.51-65). São Paulo: Casa do Psicólogo.

Oliveira, A. A. M. A. de, Cerqueira, E. M. M., \& Souza, J. S. (2003). Sobrepeso e Obesidade Infantil: Influências de Fatores biológicos e ambientais em Feira de Santana, BA. Arquivos Brasileiros de Endocrinologia \& Metabologia, 47(2). Recuperado em 15 de mar 2005, as SciELO (Sientific Eletronic Library On Line): www.scielo.br

Organização Panamericana da Saúde. (2003). Doenças crônico-degenerativas e obesidade: Estratégia mundial sobre alimentação saudável, atividade física e saúde. Organização Mundial da Saúde. Brasília: OPAS.

Pinheiro, A. R., Freitas, S. F., \& Corso, A. (2004). Uma abordagem epidemiológica da obesidade. Revista de Nutrição, 17(4). Recuperado em 15 de mar 2005, as SciELO (Sientific Eletronic Library On Line): www.scielo.br

Rego, T. C. (1995). Vygotsky: Uma perspectiva histórico-cultural da educação. Rio de Janeiro: Vozes. 
Rodrigues, É. M., \& Boog, M. C. F. (2006). Problematização como estratégia de educação nutricional com adolescentes obesos. Cadernos Saúde Pública, 22(5). Recuperado em 15 mar. 2005, as SciELO (Sientific Eletronic Library On Line): www.scielo.br

Spada, P. V. (2005). Obesidade infantil: Aspectos emocionais e vínculo mãe/filho. Rio de Janeiro: Revinter.

Recebido em: 14/03/2007

Received in: 03/14/2007

Aprovado em: 05/05/2007

Approved in: 05/05/2007 